\title{
Nature of Mediatization of Sino-Kenya Relations by the Kenyan Mainstream Press
}

\author{
Josphat Ogweno Okech* John Oluoch Fredrick Ogenga \\ School of Information Communication \& Media Studies- Department of Communication, Journalism and Media, \\ Rongo University, PO box 103, Rongo, Kenya
}

\begin{abstract}
Theoretically, the Kenyan press tends to be superficial in mediatizing Sino-Kenya relations. The tightening, multilevel and overarching social, political and economic relations are to a certain extent dependent on a critical analysis of the Kenyan mainstream press. The relation however is exhibited by the Kenyan mainstream press superficially and therefore the need to have a critical analysis of the selected newspapers. The study used the political economy and the mediatization theories to critically explore and get the discourses in the selected Kenyan Newspapers' mediatization of Sino-Kenya relations. This study therefore aimed at investigate the nature of Sino-Kenya relations in Kenyan mainstream press mediatization of Sino-Kenya relations. The study sought to answer the following question, what is the nature of Sino-Kenya relations as mediatized in the selected Kenyan mainstream press? An explorative research design approach was adopted to address the question of meditization by the mainstream press on Sino-Kenya relations. The identified nature of mediatization were found to be fused with ideological undertones that served in mediatizing the Sino-Kenya relations. The results indicated that articles adopted neutral tone whose implication was a dual beneficial relation.
\end{abstract}

Keywords: Mediatization, Media discourses, Meaning, Sino-Kenya, Press

DOI: $10.7176 / \mathrm{NMMC} / 97-04$

Publication date:August $31^{\text {st }} 2021$

\section{Introduction}

To date, western media globally have mostly narrated the story of China's engagement. Western media mostly look at China with suspicion on global level and it is regarded as an exploiting power on African continent Taylor, I. et al (2014). Often, it is framed in the context of land-grabbing, resource-snatching, neo-colonialism, and invasion.

Since the turn of the $21^{\text {st }}$ century, Western media have begun to focus on an emerging economic power the People's Republic of China. According to Le Pere, (2007), China has the potential to "grow into a power which is able to end the current unipolar system of U.S. dominance," as China is focused on increasing its economic, political, and military power. China's competition with the U.S. has been particularly evident in Africa in recent years. For decades, China's relations with Africa had focused on "checkbook diplomacy" providing aid in exchange for diplomatic recognition of Beijing instead of Taiwan (Bräutigam, 2011; Sun \& Olin-Ammentorp, 2014). However, China has now shifted its approach by increasing trade and investment, rather than focusing solely on aid to achieve its policy goals abroad. China's progressive push into Africa has drawn considerable scrutiny from Western leaders, which is further perpetuated by Western media who criticize China's environmental and labor standards, as well as China's no-strings attached policy, which advocates noninterference in the countries with which it partners Bräutigam, (2011). To counter such negative news reports, China has embarked upon public diplomacy initiatives designed to improve its image, including an influx of Chinese news bureaus in East Africa (Taylor, I. et al 2014)

The Changing Nature of Sino-African is understood in the analysis distinguishes between four different periods depicting the evolution of Sino-African relations since the creation of the People's Republic of China (PRC) in 1949. The chosen periods reflect both the political and economic perspectives of this relationship, particularly the major underlying forces that underpin this relationship. The periods also reflect how the political and economic dimensions of this relationship have changed over the past decades as China develops into the global power, and the second largest economy it is today. China's contemporary relations and engagement with the African continent are widely recognized (Large, 2008).

However, it is worth noting that the 'dragon' has not just arrived (Jiang, 2009). African countries have more than half a century of interactions with China (Achberger, 2010) that can be related to certain historical periods. Each period is characterized by political or economic factors that have helped shape the nature of this relationship over the past five decades as well as presently: the era of self-determination, the era of open door policies, the post-Tiananmen Square era and the period after the launch of the 'Go Global' policy. The final period may be described as the period of the formulation, and implementation of the 'Go Global' strategy from the year 2000 and onwards. The birth of this policy marked the rising strength of the Chinese economy and notably the birth of the CMNE - highly competitive, and prepared to engage in value-added activities in various locations of the world wherever the opportunities arise. Such an approach to FDI meant that African countries 
despite their highly risky environments for business became a popular destination for Chinese capital due to its wealth in energy, and natural resources Jiang, (2009). Thus, the beginning of the $21^{\text {st }}$ century witnessed a significant re-engagement with Africa both politically and economically on a scale never seen since the time of the Bandung conference of 1955. We elaborate on each of the above four periods of the Sino-African relations below showing how the relationship has evolved over the decades to China's current re-engagement with Africa. The recognition of the People's Republic of China in the United Nations had much to do with the votes of 26 African countries in the United Nations Wei, (1982), thus marking the event as perhaps the most significant in Sino-African relations.

However, the media in Africa have also often been accused of promoting various negative effects on their audiences, such as violence, discrimination and conflict (Kamau, 2007). These allegations are based on the assumption that media discourse is important in shaping the images and events as received by their audiences. Thus, how the media report about various social issues affects not only their audiences understanding of them but also what they perceive to be the right way to relate to these issues. This line of thinking is further enhanced by the growing realization that media is often not a mirror of reality, but rather a mediatization of the world, and that all these mediatization being selective make it impossible to have an absolute truth about media representations (Schudson, 2003). Therein then lays the need in continuous examination of the various mediatization mechanisms/nature employed by the media (Schudson, 2003).

It is against this backdrop that the Kenyan press have actively mediatized on Sino-Kenya relations. However, questions bordering on the depth of their content have continued to be raised, based on how they have covered the China-Kenya relations (Tull, 2006). For example, a study conducted by (Neuendorf, 2002) on some of the mainstream media outlets discovered that the press, because of their need to fill the newspapers with content and working in an environment where they have to compete for the scope, have been in a hurry to report on the China-Kenya relations with each development deemed newsworthy which in turn may have greatly impacted on the quality of information provided (Neuendorf, 2002). This then sets the stage for further analysis of the mainstream press content to decode the overarching mediatization of China-Kenya relations by the Kenyan press to establish the depth of the messages received by the Kenyan public regarding it.

The Sino-Kenya relation dates back to $14^{\text {th }}$ December 1963 , when China opened her embassy in Nairobi (Kamau, 2007). According to Onjala (2008), the Chinese embassy in Kenya is arguably their largest embassy in Africa both in terms of size and employees. The early post-independence period saw fairly developed bilateral ties between the two countries. However, after 1965, this relation was lowered to the level of agency diplomacy when Kenya declared the Chinese charge' d' affaires persona non grata ordering him out of Kenya. In response China expelled the Kenya charge'd' affaires (East African Standard, Nairobi, 8 June 1967, p. 6). Nevertheless, towards the beginning of the $1970 \mathrm{~s}$, it gradually began to return to normal diplomatic relation as they restored the embassy relationship (Onjala, 2008).

According to Mingxun \& Robertson, (2013) China has enhanced its presence in Kenya in infrastructure such as the construction of the Nairobi-Thika superhighway. China also established Confucius institutes in local universities such as Kenyatta University and University of Nairobi to teach Mandarin. Other areas of aid provided by China to Kenya include renovation of the Moi International sports Centre Kasarani, methane generating pit and the expansion project of Moi Teaching and Referral Hospital in Eldoret. Kenya was also granted the preferred Tourist Destination in 2004, thus arrivals from China have doubled (Kaplinsky, 2007). In 2012, an estimated 41,000 Chinese visited Kenya for business and pleasure (Odhiambo, 2012). There have also been increased Foreign Direct Investment (FDI) in Kenya by the Chinese business community in the fields of infrastructure, education, agriculture and mining (Onjalla, 2008).

\section{Statement of the Problem}

Theoretically, the Kenyan press tends to be superficial in mediatizing Sino-Kenya relations. It is important therefore that the Kenyan mainstream press goes beyond the superficial mediatization of events on Sino-Kenya relations to play both a critical, inclusive, democratic and developmental role that suits the African continent. The tightening, multilevel and overarching social, political and economic relations are to a certain extent dependent on a critical analysis of the Kenyan mainstream press. The relation however is exhibited by the Kenyan mainstream press superficially and therefore the need to have a critical analysis of the newspapers. The media in Africa has often been accused of promoting various negative effects on their audiences, such as violence, discrimination and conflict (Kamau, 2007). These allegations are based on the assumption that media discourse is important in shaping the images and events as received by their audiences. Thus, how the media report about various social issues affects not only their audiences understanding of them but also what they perceive to be the right way to relate to these issues. This line of thinking is further enhanced by the growing realization that media is often not a mirror of reality, but rather a mediatization of the world, and that all these mediatization being selective make it impossible to have an absolute truth about media representations (Schudson, 2003) therein then lays the need in continuous examination of the various mediatization 
mechanisms/nature employed by the media (Schudson, 2003; Lynch \& McGoldrick, 2005).

It is against this backdrop that the Kenyan press have actively mediatized on Sino-Kenya relations. However, questions bordering on the depth of their content have continued to be raised, based on how they have covered the China-Kenya relations (Tull, 2006). For example, a study conducted by (Neuendorf, 2002) on some of the mainstream media outlets discovered that the press, because of their need to fill the newspapers with content and working in an environment where they have to compete for the scoop, have been in a hurry to report on the China-Kenya relations with each development deemed newsworthy which in turn may have greatly impacted on the quality of information provided (Neuendorf, 2002). This then sets the stage for further analysis of the mainstream press content to decode the overarching mediatization of China-Kenya relations by the Kenyan press to establish the depth of the messages received by the Kenyan public regarding it.

\subsection{The Nature of Mediatization}

The press often employs the art of mediatization in their endeavor to inform and educate their audiences. Mediatization is the process whereby society to an increasing degree is submitted to, or becomes dependent on, the media and their logic (Hjarvard, 2008). Hall, (1997) describes mediatization as made up of two different systems; mental representation and language representations. This study focuses on mediatization through language, where language in this context refers to the written, spoken and visual nature used in the communication process. Hall (ibid), posits that representation through language helps us to make sense of the world we live in, and we are able to express a complex thought about these things to other people or communicate about them through language in ways through which other people are able to understand them. According to Mackay, (1997), any sound, word, image or object which functions as a sign and is organized with other signs into a system which is capable of carrying and expressing meaning is language.

The press uses various mechanisms/nature such as tone, antinomies, framing, images/photos, anchoring and metaphors, to enhance their art of mediatization. This study focuses on tone, antinomies, images and metaphors as advanced by the theory of mediatization Hjarvard, (2013). By analysing them, these concepts can be used in understanding how new mediatization is developed when variousnature of mediatization are included in a message (Strömbäck \& Esser 2014).

Mediatization therefore play an important role in communication because the mechanisms allow an issue to be debated, rejected or defended, depending on an individual's interests and motivations. Conversely, van Dijk, (2000) posit that an analytical approach to the study of mediatization can expose how these processes function discursively in the domain of media text through the analysis of print media. This approach has similarly been used in the current study to identify and decode the various mediatization mechanisms of the Sino-Kenya relations as advanced by The Daily Nation, The Standard and The Star newspapers.

Ergo, mediatization can potentially serve as an overarching theoretical framework to understand the overtime change in the coverage of negative incidents and the observed patterns in the findings from previous research with different theoretical starting points. In order to explore whether the press increasingly portray the world in terms of menace rather than accuracy, this study's overall goal is to map the longitudinal process of the press attention to and coverage of China-Kenya relations.

\section{METHODOLOGY}

This study investigates how China-Kenya relations is mediatized in The Daily Nation, The Standard and The Star newspapers, using the philosophy of interpretivism that explores the rationale in issues raised about SinoKenya relations. In contrast, the philosophy of positivism is used to provide the study with the required information, such as reflections or intuitions of issues of Sino-Kenya relations. However, the cornerstone of this research is the interpretation of frames/themes in order to explain the motives and purposes behind decisions of newspaper mediatization. This can best be done by means of text analysis, which will help the researcher to understand situations or positions that dictate the relevance of news creation in the newspapers, which is the main subject of the study.

\subsection{Research Design}

An exploratory design was adopted in this study. Creswell, (2008) described as a collection of Sequential procedures, in which the researcher seeks to elaborate on, or expand, the findings of one method with another method. The design is appropriate for this thesis because it helped do an in-depth analysis of the way the meanings of the emerging discourse in the selected newspapers mediatizes Sino- Kenya relations. This method is ideal because my study is based on a critical discourse evaluation of contents in the study. This involved beginning with a qualitative method for exploratory purposes and following up with a quantitative method with a large sample so that the researcher can generalize results to a population. Alternatively, the study begun with a quantitative method in which theories or concepts were tested, and was followed by a qualitative method involving detailed exploration with a few cases or individuals. 
The rationale for using this approach was that the quantitative data and their subsequent analysis gave a general conception of the research problem in the current study, which explored on the issues that Sino-Kenya relations face and how they were mediatized by the selected Kenyan newspapers. The qualitative data collection and analysis elucidated on these statistical findings by exploring the meaning of the data in more depth, Creswell, (2003). Many researchers explore the merits and demerits of the mixed methods research approach (Creswell, 2003; Moghaddam et al., 2003). The merits of this method include straight forwardness and increased opportunities for the discovery of the quantitative findings in a specific way. However, the limitations of this design include the length of time taken and the feasibility of resources needed to collect and analyse both types of data, (Ivankova, 2015).

\subsection{Study Area}

The study area was the Kenyan mainstream press, where The Standard, The Daily Nation and The Star newspapers. Print media was selected because there is significant evidence showing that newspapers in particular, regularly serve to shape popular attitudes and beliefs, as they act as agents of public education (Baillie, 1996).

Within the newspapers, the study focused on whole article. These articles consisted of hard news, reports written by reporters or journalists, with the aim of providing neutral and objective accounts of a particular issue. Hard news is fast paced news that is heavily promoted by newspapers and usually appears on the front pages of newspapers (Schudson, 2003).

\subsection{Target Population}

In research, the term 'population' does not necessarily mean people; it can be texts, institutions, or anything else under investigation. A population of interest is dependent on what the researcher is investigating (Deacon et al., 2007). Generally, qualitative research design does not generate data that can be generalized to a greater population. Therefore, the selected sample of analysis is from a population deemed to be suitable to address my research objectives. In my study, the population of interest is the articles and news about Sino-Kenya relations that made headlines in three selected newspapers; The Daily Nation, The Standard Newspaper and The Star published between 2014 and ending 2019 covering a period of five years. It is from these targeted newspaper copies that the researcher relied on as an accurate and representative population for study. For the interview segment, the target population was 808 accredited journalists; 390 from The Standard Media and 378 from Nation Media and 40 from the Star newspapers respectively (Media Council of Kenya, 2020).

\subsection{Sample size}

Previous studies on getting a sample size for newspaper analysis, beginning with Stempel's in 1952, have shown that the cyclic nature of media content can render simple random sampling inefficient (i.e., more editions must be sampled), compared to other types of sampling. For example, daily papers vary from day to day during a week because of the advertising cycle, and simple random sampling can over-sample large-news whole Wednesday and Sunday editions and under-sample scanty Saturday editions.

This study used purposive sampling because, according to Krippendorff, (2003), newspaper units are counted purposively and content analysts can use sample letters, terms or issues of a newspaper to answer research questions by enumerating sentences or interpreting details. The Researcher searched for Keywords used in this data to come up with a sample size: "Sino-Kenya! Or China-Kenya relations or Sino-Kenya relations!" Only articles that directly related to China's engagement in Kenya were included in the analysis. The results of the search were screened in order to eliminate duplicate and irrelevant results. The initial keyword search of articles found 50 articles of the Daily Nation and 70 news articles of The Standard and 30 for The Star. After removing 80 duplicated and not relevant articles, 70 articles were identified and focused on the topic of China's - Kenya relations. Among them, 20 articles were published by the Daily Nation and 40 articles appeared in The Standard and 10 The Star. The specific data analytic steps employed conducted the thematic analysis are as follows: first, retrieved the most relevant news articles used the combination of search words mentioned above. Then, each news article was read carefully to underline aspects of the texts that were relevant to China's current engagement in Kenya. Next, a second immersive reading was conducted to take notes of recurrent themes of China's presence in Kenya that were selected and narrated by the newspapers. Finally, a repeated reading of each text was done where themes were clarified, and important meanings were distinguished. News texts from both newspapers were constantly compared to distinguish the similarities and differences between their coverage.

Researcher read each article and the 70 that met any of the following exclusion criteria: article is from daily edition; article is from the news articles, sports, opinion pages, commentaries; article should have a word count of 50-3,000 words. The exclusion criteria were chosen to ensure that the sample contained only news articles relevant to the issue of Sino-Kenya relations. Following the application of the exclusion criteria therefore 70 articles remained. The majority of the sampled articles were collected from an online resource. Articles on the 
two newspapers were collected from the on-line archive and newspaper websites and some from hard copies. The basic unit of analysis was whole news story. The coding instrument consisted of the name of the newspaper, year of publication, themes of news stories, major issues closely related to Sino-Kenya relations and three news frames in the study.

The sample size for the newspapers was obtained using the researcher's own formula given as:

Daily Nation newspaper before screening (n 1$)=20$

The Standard newspaper before screening (n 2) $=40$

The Star newspaper before screening (n 3$)=10$

$\mathrm{N}_{1}=1823$ (Nation)

$\mathrm{N}_{2}=1823$ (Standard)

$\mathrm{N}_{3}=1823$ (Star)

$\frac{\mathrm{N} 1}{\mathrm{~S}_{K^{1}}}=20, \frac{\mathrm{N} 2}{\mathrm{~s}_{K^{2}}}=40$ and $\frac{\mathrm{Na}}{5_{K^{3}}}=10$

Where $S_{K^{1}}=$ Screened stories on Sino-Kenya relations in the Daily Nation

$S_{K^{2}}=$ Screened stories on Sino-Kenya relations in the Standard newspaper

$S_{K^{8}}=$ Screened stories on Sino-Kenya relations in The Star

$\mathrm{n}_{1}=\frac{N}{S_{K^{1}}}$ (Nation) and $\mathrm{n}_{2}=\frac{N}{S_{K^{2}}}\left(\right.$ The Standard) and $\mathrm{n}_{3=} \frac{N}{S_{K^{3}}} S_{K^{1}} \simeq 91$ and $S_{K^{2}} \frac{\max }{46}$ and $S_{K^{3}} \frac{\max }{182}$

$\mathrm{n}=\mathrm{n}_{1+} \mathrm{n}_{2+} \mathrm{n}_{3}$

Therefore, the sample size is given as $n=\left\{\left(\frac{N}{S_{K^{1}}}\right)+\left(\frac{N}{S_{K^{2}}}\right)\right\}$

$\frac{1828}{9119}+\frac{1828}{45.58}+\frac{1828}{1828}=69.99$

$n \simeq 70$

Taking into consideration that an almost similar study on a Comparative Analysis of Chinese, Western and African Media Discourse in the Representation of China's Expansion of Economic Engagements in Africa by Wei, (2015) conducted 4 qualitative interviews, this study sought to balance between recommendations and practice and hence settled on 4 participants for the interview. And 3 Chief editors drawn from each of the newspapers in the study.

\subsection{Sampling Procedures}

Sampling was completed in two stages. First, the amount of published material relating to Sino-Kenya relations was narrowed down, and second, the content for analysis was selected from all the units in the sampling frame using a list of the frequency of common words to observe if they are related to the main issue of the news story. The material collected from the newspapers was divided into two steps. First, every news story about SinoKenya from 2015 to 2019 was collected from the two specified newspapers. This step helped to determine how many news stories were published, and what types of issues were addressed and how the newspaper deal with the information sources. Second, two of the most common issues were chosen for the study and visual and text analyses were carried out to discuss the type of predominant themes therefore a sample of 70 newspapers were considered

This sample period is considered appropriate for the present study because it covers a variety of media content that spans a wide area with sufficient content of China's engagement in Kenya. Editorials, news, and features articles will be the units of analysis because theme analysis favors whole articles as the main discourse unit (Umejei, 2013).

Testing sampling efficiency for inferring to a five-year population of newspaper editions required three steps: (1) calculating population parameters for the five-year population; (2) drawing random stratified

samples in sets of 50 for various numbers of weeks and calculating how well they estimate the population parameters; and (3) determining which size (number of weeks) stratified samples were most effective.

Purposive sampling technique, was used which demanded that only two reporters/journalists be selected because they were the people of interest in the study by virtue of their position as key gatekeepers. The study was concerned with finding out the factors that influenced the selected newspapers mediatization of the SinoKenya relations from the producers or those who act as gatekeepers of such texts.

The sampling procedure entailed a three step approach as proposed by Newbold et al., (2002), involving first the selection of media form and genre, then selecting the period that formed the parameters of the study and 
finally sampling relevant content from the selected newspaper copies. In this study, three newspapers were selected for analysis and the genre of the articles analysed were whole story articles.

This study follows Kaitlynn Mendes's logic in using newspapers for the data collection instead of any other medium such as Television or Radio. With regard to this preference Kaitlynn Mendes argued that she:

“...selected newspapers because their daily publication and wide circulation give them potential for quickly disseminating timely information about the women's movement to millions each day. Newspapers also present a forum for many types of styles - news, features, editorials, comment, letters to the editor comment, advertisements and cartoons - all in the same publication" (2011)

\subsection{Data Collection Instruments}

Both primary and secondary data were used in the study. Primary data was obtained by reading through the sampled news articles in order to identify the information needed in the study that eventually provided the data that was analysed. The unit of analysis was an entire news article including any photograph in it. A coding sheet was used to identify page lead stories relevant to the research question and research objectives. The coding sheet was employed to reduce the newspaper content into categories that were consistent with the objectives of the research. The coding categories used in the study were determined by the tenets of the mediatization theory; tone, discussions, photographs and themes. The categories helped in identifying the various mediatization mechanisms used by the newspapers and to analyse how the mechanisms were used in the news stories. The sample was used for analysis to determine the objectives and derive findings in this research.

\subsection{Interview Schedules}

Interview schedules was used to allow changes in the questions, seek clarification from the respondents' (Reporters) and the editors and was more personal to allow respondents give their opinion on Sino-Kenya relations in determining their editorial policies in regards to publishing articles that relate to Sino-Kenya relations

\subsection{Content Analysis}

Content analysis assesses forms of human communication, including books, newspapers and films, to identify patterns, themes or bias (Leedy \& Ormrod, 2010). Content analysis identifies specific characteristics from the content by verbal, visual and behavioural pattern analysis (Williams, 2007).

Content analysis is a research method, which offers researchers an effective way to investigate media content, (Cooley, 2011). Hansen et al described content analysis as, "a research technique for the objective, systematic and quantitative description of the manifest content of communication." This analysis identifies and counts the amount of specific characteristics of text in order to be able to say something about the messages, images, representations of such texts and their broader social significance (Hansen et al., 1998). In this study, content analysis helped the researcher to understand the content of the newspaper-specific coverage of the SinoKenya relations. The purpose of using content analysis in this study is to independently extract subject from the cultural products related to media production (Leavy, 2000).

The content analysis tool was used to identify articles in the news and opinion pages that tackled areas that represent Sino-Kenya relations. The presence of such articles and their quantification provides an understanding of how China engagement in Kenya articles were displayed and covered. The quantification was accomplished by counting the number of stories in each of the Sino-Kenya relations themes that appears in the press. Quantification of the articles was performed by counting the frequencies of appearance in the selected pages. As mentioned earlier, the newspapers could be mediatizing themes on Social, Political, and economic relations. The three thematic issues were scored a point each, based on their frequency of appearance on The Daily Nation and The Standard dailies edit levels of newspaper articles, giving a total of three thematic levels. In addition, content analysis was to determine the level of importance that was attached to specific themes in the Sino-Kenya relations by conducting an analysis of the positioning of the articles in the newspaper under study. Coding was concentrated on articles that dealt with the editorial, political leaders, and citizens' utterances.

\section{DATA ANALYSIS, PRESENTATION AND INTERPRETATION}

The main objective of this study was to examine the mediatization of Sino-Kenya relations in the selected mainstream newspapers in Kenya. This chapter therefore, presents the data, analyses them and discusses the findings in order to answer the three objectives of the study

\subsection{The Nature of Mediatization as Used in the selected newspapers to Mediatize Sino-Kenya Relations}

As already discussed in chapter 1, when employing the mechanisms of mediatization, the media will often use nature such as tone, antinomies, photographs/images and metaphors, to aid in mediatizing an issue in ways through which their audiences can easily understand them (Markova, 2003). Thus, the current study also sought 
to find out whether the newspapers used this nature in order to enhance the mechanisms of mediatization, in their representation of Sino-Kenya relations.

\subsection{Tone Analysis}

The overall tone of the discourses surrounding the countries in our sample was coded as positive, negative or neutral - an important feature as it tells us how much of the coverage could be regarded as 'positive', 'neutral' or 'negative' news. This is an important investigation, as it is a widely held perception that most media coverage of the developing world is "negative". This analysis focused on discerning the extent to which newspaper items displayed overtly positive or negative tones. In cases, where such tones were not discerned, the newspaper item was coded as evidencing a "neutral" tone. "Tone" refers to the way sources express themselves; what they decide to say and how they say it. Mc Combs, (2011), assert that tone is a major part of mediatization. They state that "News stories are both denotative messages conveying tone and emotion.

Therefore, in this case, a story is considered to have a positive tone when it focuses on the good aspects of China -Kenya relations, when it uses pleasant words and generally portrays an optimistic view of the relationship. A negative tone would be the exact opposite and may include use of harsh words, critical view and focus on the unpleasant aspects. Tone analysis was used to determine whether the stories about China-Kenya in the selected newspapers were covered positively or negatively or neutrally.

Figure 4.2: Tone of reporting Stories on Sino-Kenya relations covered in the Selected Newspapers

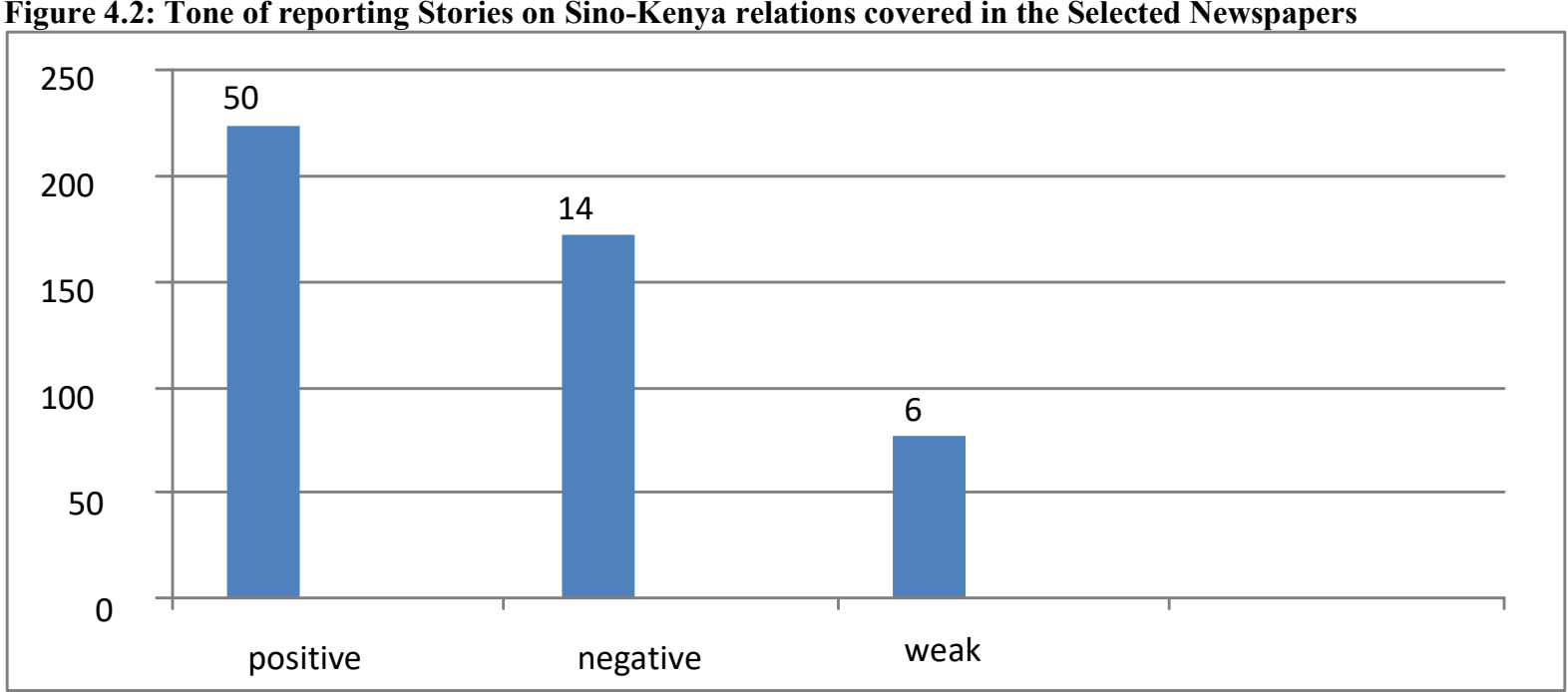

Figure 4: Overall Positive, Negative and weak tone (note that vertical axis represents the number of stories)

The study found that the image of China in Kenya is positive rather than, negative and weak. However, when we compare positive and weak codes, the margin is substantially bigger. As we will explain, mediatization theorists tend not to take into account the possibility of neutral tone, only weak ones. In other words, you cannot have perfectly balanced or non-existent feelings about China. For instance, if we assume that there is a Kenyan reader who has not heard about China at all, to the extent that a China headline draws absolutely no feelings from him or her, this hypothetical reader would frame the article in an extremely weak sense rather than completely neutrally. An average reader who sees a 'weakly framed' headline, that is, one that is neither explicitly negative nor unequivocally positive may either have a positive or negative perception. Thus we may assume that weak frames can be read as positive or negative depending on the reader's prejudices. China enthusiasts will see a weak headline only in positive light; China-bashers will see a weak headline only in negative terms. Weak frames can therefore be seen as positive or negative depending on the disposition of the reader. Thus, when we contextualize weak tone in relation to positive and negative tone, we see that the image of China equally fluctuates from potentially very positive to potentially negative.

Majority of the newspapers had a tone that supported Sino-Kenya relations 50 stories in the selected newspapers gave a positive response for both the states being in the relationship but 14 stories gave negative tone of response for example "Unfavorable China-Kenya trade leaves KSh 380 billion gap- The Standard Wednesday, 25 June 2019. Another story that was among the four that criticized Kenya in the relationship was "Fact Checker: Trade with China skewed against Kenya by Franklin Sunday on The Standard Friday, April 2nd 2019.

6 stories representing $18 \%$ did not support Sino-Kenya relations by giving a weak tone in the reportage for example, in February 2008, Mr. Okech Kendo of the Standard wrote an article "China has proved it's not a friend to count on" based on some misunderstandings or incomplete information. H.E. Mr. Zhang Ming, Chinese 
Ambassador to Kenya wrote this article" China's acts prove it is a friend Kenya can rely on to response and explain China's position to the post-election crisis in Kenya. The Standard Monday March, 12 ${ }^{\text {th }} 2018$. Despite having stories that would generally be considered negative in nature, Sino-Kenya relations still ended up being framed in a positive tone in majority of stories. For instance, the Article "China-Kenya cooperation headed for a brighter future - Daily Nation Tuesday April, 23 2019'by Andrew Moody, despite the fact that Kenya's economy is slowing down, the story has a positive tone to suggest that this is not just a concern for Kenya but for China. The deputy director and professor of finance at the Shanghai Advanced Institute of Finance is quoted saying "China is now so integrated into the global system, that whatever happens to its economy is headlines everywhere, and that Africa is unlikely to escape" He adds "China accounts for a quarter of global growth. We have reached a stage where you cannot fully understand the global economy without understanding the Chinese one".

Another story that would generally be considered negative in nature, manages to mediatize China in positive light and apportion blame and the negative aspects to a second party. The Article "Businesses cite biggest barriers in Kenya" by Li Lianxing coded 5/12/09/E/32 begins the first paragraph by saying "Chinese investors and potential investors have long regarded a good China-Kenya relationship as a solid basis on which they can build success. But often when the uninitiated finally step onto the Kenyan soil they realize how simplistic the term "China-Kenya relationship" really is. It goes on to report that "Fifty-three percent of the 75 Chinese companies sounded out in the survey said corruption is "a very significant obstacle" to doing business in Kenya, and 15 percent said it is "a significant obstacle". Sixty-three percent of respondents said crime, theft, disorder and personal safety were significant or very significant obstacles.

Another story that would generally be considered negative in nature, is the Article "Kenya getting raw deal from China, says new World Bank trade report" by Li Lianxing coded 5/12/09/E/32 has a paragraph saying "And while China is currently Kenya's largest trading partner, Chinese imports far exceed what Kenya sells to the world's second-largest economy. Imports from China have dramatically increased from 12 per cent in 2012 to 23 percent in 2014". It goes on to report that "Kenya sends only 1 per cent of its exports to China, which include raw hides and skins, scrap metal, coffee and tea. And because Kenya's agricultural sector lacks competitive advantage in China's main food market, it has been difficult to increase sales of more local produce". The report says that "even more telling is the fact that Kenya exports less to China than to economies of a similar size. For every $\$ 100$ (Sh10,170) Kenya exports to an economy similar to the Asian nations, it only exports $\$ 82($ Sh8,340) to China.

In addition, as we have seen in previous sections, readers are likely to be in favor of China in certain circumstances or topics and to disfavor it on others. The researcher thus categorizes a headline for example in the negative category along with, say, Chinese chicken farmers ruffle Zambian feathers (Daily Nation, February 9 2017). Is Kenya ripe for marriage with China? (Daily Nation, October 12 2016) is a weak headline to the extent that it is a rhetorical and ambivalent. The use of the word 'grip' would indicate a quite negative perception, except that the segment referring to a KSh 4 billion [ $\$ 46.7$ million] deal lends a positive tone. This is a hefty figure by Kenyan standards -thus the presence of negative and positive attributes renders the headline 'weak' in line with definition of the parameters for this paper.

The general tone of reporting is positive $81 \%$ of the Articles and news stories sampled and those that appear negative in nature was $18 \%$. These findings suggest that themes not only carry specific views but also influence how the audience perceives a matter of how they can be oriented towards an issue.It can therefore be interpreted that there is a deliberate strategy to shape the mediatization of newspaper readers and influence their attitudes towards China's engagement in Kenya by presenting a positive tone and impression. The researcher's conclusion is resonant with Wesserman (2011) findings, that is, a more or less balanced image of China is discernible in Kenyan media. Although my findings are that the media image of China is more positive than negative, $i$ also found that the margin between positive and negative tone is not too wide. In broad terms, my conclusion affirms that the image of China in Kenya is more or less balanced between negative and positive perceptions because of the interplay of both negative and positive media tone.

\subsection{Photographs/Pictures}

Visual analysis was used to assess the nature of physical content in the newspapers and, more specifically, to examine the presence of stereotypes and determine their effects on viewers' understanding of Sino-Kenya relations. Visual analysis attempts to discern literal from non-literal uses of photographs and their underlying symbolic meanings (Weiland and Ponzetto, 2009). Visual analysis evaluated the role played by images in a study by (Onjala, 2008). Leon and Erviti, (2013) appraised this type of analysis, explaining how photos are used to shape publications and how they influence the mediatization of Sino-Kenya relationship.

This study followed visual analysis as described by Leon and Erviti, (2013) to analyse photographs that are synchronous with texts in publications on Sino-Kenya relationship by the two Kenyan newspapers. Although the research did not focus on the observable frames in photographs and their associated framing analysis, it 
examined how the two selected Kenyan newspapers represented Sino-Kenya relations using content analysis. Additionally, quantitative content analysis of the photographs provided a greater understanding of the mediatization of Sino-Kenya in the news and thus provided a deeper understanding of the portrayal of the relations. Photographs were used as strong evidence of how newspapers mediatized Sino-Kenya relations. According to the mediatization theory, the media when using the mechanisms of mediatization may use photographs to help in explaining new phenomena in emotions that are easily understood by their audience. This in turn makes it easier for the audience to make sense of the phenomenon by attaching emotions to the photographs they see. Photographs play an important role in newspaper texts, and as Engel, (2008) posits, newspaper photographs are sometimes the most salient hooks that draw the reader to a particular story. Thus, newspapers do not merely use any photograph to accompany a text, but they use those that can draw the attention of the reader to the text or those that have significant messages in them (Engel, 2008).

Similarly, media scholars (Hoijer, 2011: Markova, 2003) posit that photographs as nature of mediatization can evoke various emotions on a reader and it is these emotions that may form the basis on which the media message is interpreted and understood. In this study, analysing the various emotions evoked by the photographs identified in the articles helped in understanding how these emotions served in the mediatization of Sino-Kenya relations.

\subsubsection{The Role of Photographs}

According to the mediatization theory, the media may use photographs to help in anchoring new phenomena in emotions that are easily understood by their audience. This in turn makes it easier for the audience to make sense of the phenomenon by attaching emotions to the photographs they see.

Conversely, in the current study and as shown in table 4.4 below, it emerged in the study that out of the 70 news articles that were analysed, 59 of them had photographs accompanying the written texts while only 11 did not have photographs all of which accompanied news stories relating to Sino-Kenya relations.

However, considering news writing as a conventional process, the photographs that were used to represent the Sino-Kenya relations were characterized by sensationalism and negativity as good news. The conventional process used thus allowed for a significant fit between the semiotic instructions of how to read news as a genre and the general message usually inferred by viewers. Thus, the photographs about the Sino-Kenya situation were anchored to match the words in order to construct meaning. The meaning constructed was that which reinforced readers' perceptions of the situation in Sino-Kenya relations rather than challenging them. The perceptions were linked to the conviction that Sino-Kenya relations is faced with a problematic socio-economic and political relations.

Falah, (2005) observed, photograph captions represent the value judgements of a newspaper's editor and can be easily transmitted. The words selected for the captions not only describe the image, but might also provide a reading of the visual representation. The editor effectively decides which message readers are meant to receive from the picture's caption.

The Daily Nation Tuesday, April 232019 provides a good example of the contradictions that can result from the representations seen in published photographs. In this particular newspaper, images of the two presidents, who appeared to be holding hands in the article showing happiness, while the by-line has a message that is contradicting.

Barthes, (1982; in Engel 2008) in his study on the functions of media photographs found that newspaper photographs are never isolated structures but often have some sort of written commentary or an accompanying text associated with the photo that illustrates the picture. These accompanying texts are captions that provide a short description of the picture is and why it has been used in the article. They help the readers understand what they see. According to him (Bathes, 1982 ibid), the text anchors the image by naming it and this anchoring function is a common practice used in mass communication.

Thus, considering the forgoing importance of captions especially in textual analysis, this study also sought to determine whether the photographs used had accompanying captions to explain them. This in turn would help/ helped in understanding how the photographs and their captions were used in mediatizing Sino-Kenya relations.

When captions photos in relation to a story, they feed the reader with information on people, time and place included in the picture (Engel, 2008). They also provide snippets of details that make the reader want to read more from the text. Captions also place a particular interpretation on the image that helps in shaping how the reader understands that image. For example, a story appearing in one of the news articles, had a photograph (Extract 1) showing "President Xi Jinping of China and President Kenyatta of Kenya holding hands as a sign of strengthening China-Kenya relations into Comprehensive Strategic Cooperative Partnership." (Daily Nation, Tuesday April 23 2019). This caption thus explains Chinese President Xi Jinping (right) welcoming his Kenyan counterpart Uhuru Kenyatta ahead of the China International Import Expo. On the other hand, Barthes, (1982) opines that when captions are not used, then a photo is opened up for varied interpretation. Similarly, when the newspapers used the ten photographs without captioning them, they risked allowing their readers to interpret them depending, for example, on their subjective inclinations 
On the other hand, Barthes, (1982) opines that when captions are not used, then a photo is opened up for varied interpretation. Similarly, when the newspapers used the four photographs without captioning them, they risked allowing their readers to interpret them depending, for example, on their subjective inclinations.

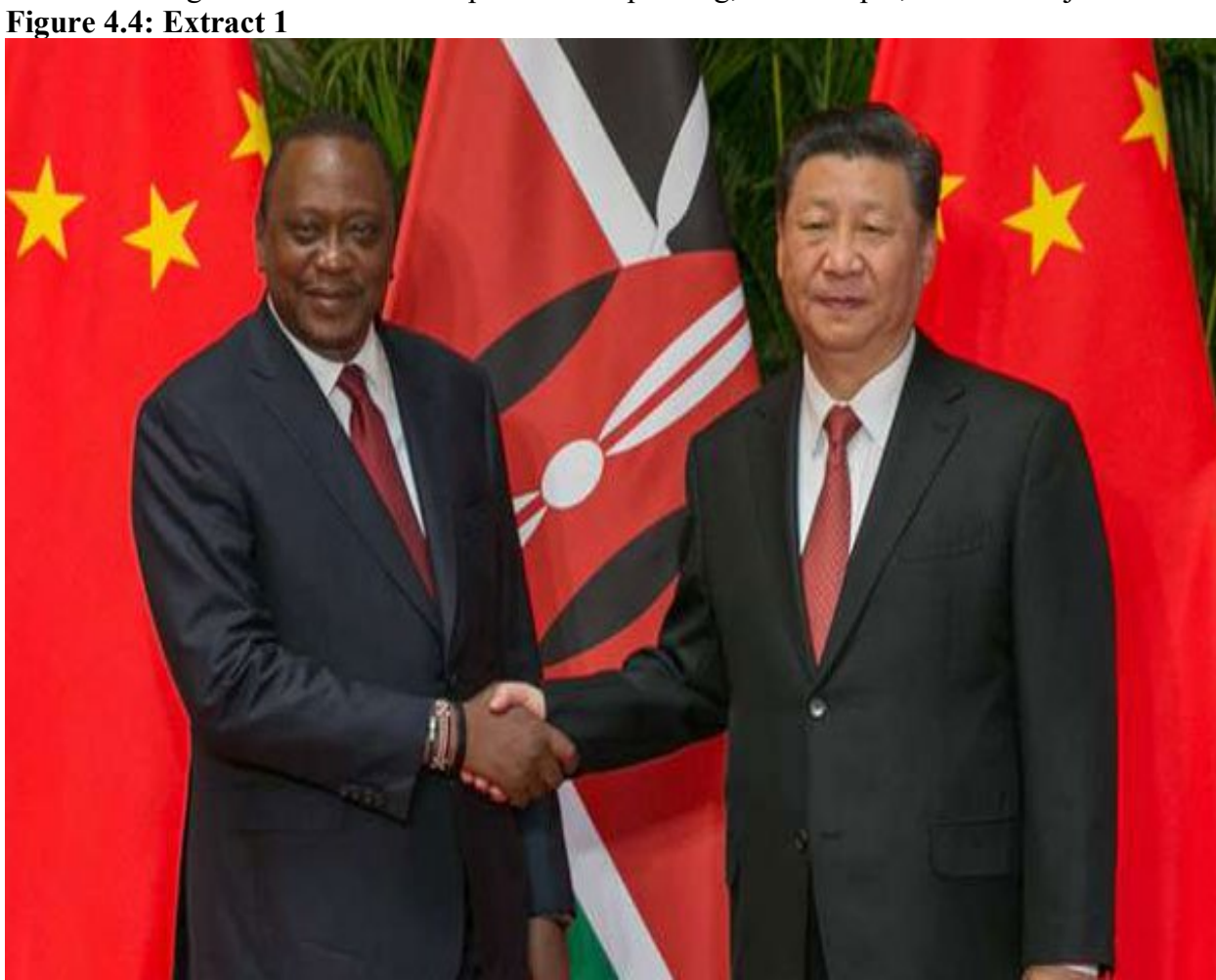

Chinese President Xi Jinping (right) welcomes his Kenyan counterpart Uhuru Kenyatta ahead of the China International Import Expo (CIIE) in Shanghai, last year. PHOTO $\mid$ PSCU

Figure 4.5: Extract 2

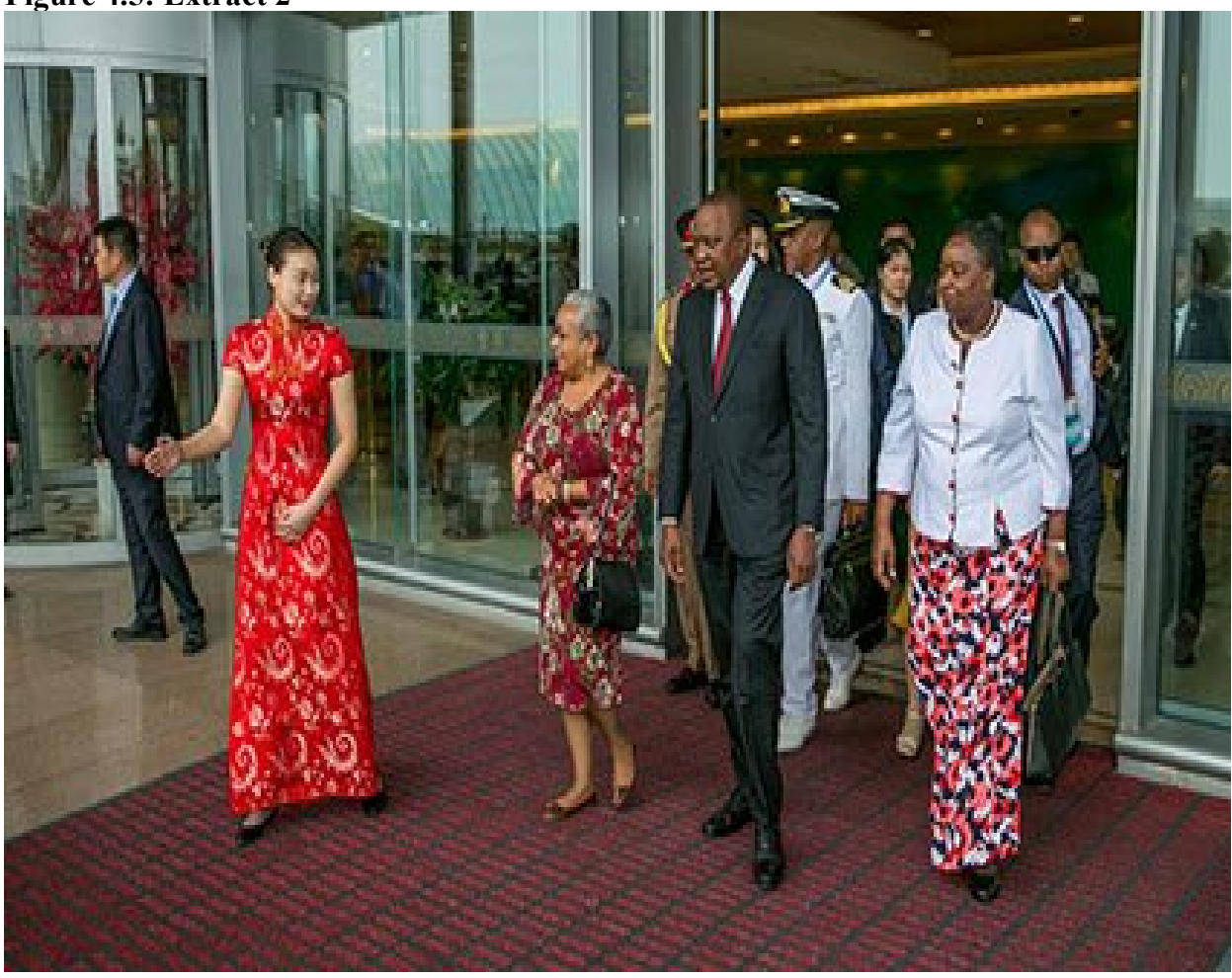


For instance, Extract 2 has a photograph-showing president Kenyatta and his entourage being led by a Chinese lady. Without a caption, is opened up for many interpretations. For example, it can be interpreted to mean that the lady is sending the president away or welcoming him in, given that the headline of the article is China-Kenya relations strong. Having many interpretations of photographs is in contradiction to the objective of using photographs as nature of mediatization, which aims at providing a common understanding of a phenomenon within the audience.

\subsection{Antinomies}

According to Oxford Online Dictionary, an antinomy is a contradiction between two beliefs or conclusions that are in themselves reasonable. Atieno, (2016).) Asserts that one of the mediatization mechanisms employed by the media is mediatizing in antinomies or in distinctions. It is a process whereby the unfamiliar is transformed into something familiar by constructing meaning when a distinction is made between two things. It often has the effect of creating sides where the audience is left to decide on which side they stand. Proponents of the meditization (Moscovici, 1984; Markova, 2003) also posit that the public often tend to relate to a new idea if it is delivered to them in opposites, where there are two opposing sides and they are made to choose a side they can relate to and support.

The most common antinomy was the one that placed Chinas' developmental motive against the perceived under developmental motives of China to Kenya, be it in the form of win-win versus individual interest. This could eventually be perceived as a 'we' versus 'them' antinomy, where the 'we' may have represented those who were against the pro Chinese narrative of win-win while 'them' represented those in support of the nondevelopmental agenda by China.

1. For example, one of the newspapers had a story that read: "China has proved it's not a friend to count on", (The Standard, February 10, 2018) or another that read: "China: China's acts prove it is a friend Kenya can rely on", (The Standard, February 12, 2018). In these two statements, the 'we' could be anyone supporting Kenya and her claims and 'them' those supporting China and her defense. For the antinomy of China versus other nations in Kenya

2. Consider for example an article with the heading: "US woos Kenya with big deals, takes swipe at China strategy", and a part of the article that stated that: "The US has unveiled a new strategy to deepen trade relations with Kenya while taking swipe at China's inroads into Africa" (The Standard, November 5, 2019). This article cites the dispute between the US and China in Kenya as a cause of negative relations between Kenya and China. It is important to note that USA is one of the countries that has always been anti-China making inroads into Africa and her position in the geopolitics.

Therefore, by using the antinomy of 'us' to represent countries from the west, and 'them' to represent China and countries from the East, the message was that the Kenyan audience/reader could identify with any of the sides and support them in the quest to cementing or not the Sino-Kenya relations. USA versus China as an antinomy was also identified in articles where the Kenyan government attempted to look for a suitable partner to relate to. For instance, one of the articles had the following statement that show the dilemma the Kenyan government had in relating to eighther USA or China: Kenya torn between China and the United States... On one side we have a powerful China offering Kenya all sorts of goodies ... her markets to our products, the relationship would be more equal" (The Standard, May 28, 2019). Another antinomy that emerged was the antinomy of Kenyan interest at the fore front versus The Chinas interest of win-win policy. For example, when an article in the (The Standard, May 13, 2014) "Irony of Kenya win-win relationship with China" ... These numbers show China has benefited 48 times more than Kenya from this win-win relationship. Kenya mainly exports leather, tea," this article compared the two countries interests with an analogy of win-win.

3. Another antinomy is brought tolight with an article that explicitly shows the rivalry between the west and China for example (The Standard, August 2, 2014)West is full of lies; China never tinkers with currency...it further goes on to say, ... disrupting the otherwise increasingly cordial Kenya-China relationship. In a rather curious piece titled: "Is Kenya a victim of alleged China ...

4. According to The Star interpretation of the Chinese presence in Africa in 2017, China is a benefactor, an investor and a moderniser. China has not only managed "to pull over 600 million of its poor citizens out of poverty in less than a generation" (DN 04.11), but it has also become "the biggest lender to Africa" (The Star November,11, 2017), "one of the most generous food donors in the world" the country which "has taken the lead role to opening up and developing the African market".

The newspapers were therefore characterized by representation of nature that foregrounded images of disagreement between those that supported Sino-Kenya relations and them that criticized the relations. Similarly, in the Kenyan context, such a representation forces the supporter of either team to look for means of stopping the perceived aggressor/state.

\subsection{Metaphors}


According to the mediatization theory, metaphors can be used to mediatize a new phenomenon by representing it within well-known subjects of life and culture (Moscovici, 2000). According to Layoff and Johnson, (1980), metaphors facilitate thought by providing a practical framework within which abstract thoughts can be accommodated and understood. Borrowing on this line of thought, the metaphoric language used by the Kenyan media under study may have played an important role in transforming the abstract issue of Sino-Kenya relations into a familiar concept by relating it to already known and understood concepts in the process of identify nature of mediatization, the study found that out of the analysed 70 articles, 56 had metaphors in them while 14 did not.

Thus the aim of identifying the metaphors used in relation to the mediatization of Sino-Kenya relations was to decode or disambiguate the sense of a word or how the word was used in the context of the Sino-Kenya relations. For example, consider an article whose headline read: "Today, China is the butt of all manner of conspiracy stories." (The Standard, May 23, 2019). The words 'butt' and 'conspiracy' can mean to hit or to destroy an object. However, based on the context in which they have been used in the article, they denote the concept of discrediting the Chinas effort and the way it is mediatized in the dailies.

Similarly, mapping of concepts was also employed as a means of determining the idea or theme brought out by the use of the metaphor (Lakoff\& Johnson, 1980). For example, an article in one of the newspapers stated that: "In the closing submissions, prosecutor Cynthia Tai went for a blow-by-blow attack on the Chineas' evidence tendered by the Kenyan (The Standard, September 9, 2011). A mapping of the concept of relationship is enhanced by the words 'torn between'. This type of identification and analysis of metaphors is in line with Shutova's, (2010) assertion that processing of metaphors can be divided into two subtasks of first recognizing the metaphor by distinguishing between its literal and metaphoric meaning in a text and second, metaphor interpretation to identify the intended meaning in a text Correspondingly, some other metaphors identified in the studied articles included an article with the headline: "Torn between China and the United States." (The Standard, May 28, 2019). In the literal meaning, 'Torn between' is to be undecided. In the context of the SinoKenya relations, this could denote taking a risk that could lead to Kenya going to eighther of the nations. Such a metaphoric phrase puts the reader on tenterhooks to want to find out the outcome of the relationship. It also portrays the Sino-Kenya relations as very difficult one where one needs to take risks. Another article had the following pulled out quote: "China, Kenya relations on firmer footing” (Daily Nation, Oct 2, 2016). Literally, 'firmer footing' refers to something that is strong and unshakable. In the context of the Sino-Kenya relations, it would denote a case of strong relations that will not be shaken by anything, because there is no possibility for the other nations coming between the two nations to spoil the already existing relations.

Thus, the following examples show some statements that had metaphors targeting the Sino-Kenya relations:

1) The headline: "Chinese market tall order for local firms" (the Standard Nov 13, 2018). The metaphoric word 'fall order' is use to represent the difficulty the relations is going through, where there are western forays or other USA coming, as a display of difficulty in the relations.

2) The Daily Nation through an article headlined: "Poor strategy dug Kenya into Chinese trade hole" had a statement that read: "Kenyan leaders." (Daily Nation, September 7, 2017). Chinas' deep pockets means giving big loans. Thus in the context of Sino-Kenya relations, it represents the process where Kenya goes dip into a hole of debt from the generous loaning from China.

4) Likewise, The Daily Nation newspaper also had a story that read: "Thanks to China the continent is a recipient of "mouth-watering" but controversial loans (The Daily Nation, December 22, 2018), the article stating that: "China's "Chequebook diplomacy" has influenced all African countries ...to have much say in global geopolitics." By using the words 'mouth-watering' the writer Erick Waminji is metaphorically mediatizing the loans to be so sweet as to lure Kenya into borrowing. The urge is also represented as being mouthwatering to mean that it is appealing and causing an excitement to borrow more loans.

Similarly, this study in seeking to determine which classes of metaphors were used in relation to Mediatize Sino-Kenya relations which relied on Kövecses', (2005) schemata for classifying metaphors. For instance, he postulates that a cultural metaphor has an activity or object with which members of a given culture can emotionally and cognitively identify with because they reflect the underlying values of a culture (Kövecses, 2005). Thus, in the current study, some metaphors were classified as cultural to Africans because they made reference to objects or concepts that could resonated well with Africans, especially Kenyans who were the newspapers target audience.

On the other hand, Ma and Liu, (2008) advance that universal metaphors are those that evoke a similar or uniform thinking pattern in different cultures. In this regard, when a person is compared to a lion, for example, the lion is universally known to be a courageous and strong animal, thus such a metaphor can be classified as universal. Similarly, in this study, metaphors were classified as universal metaphors when they made reference to objects that could be interpreted in almost a similar way by different audiences regardless of their geographical location. Other metaphors were also classified as westernized whenever the references used were those that were available in the west culture, thus resonating with the western or European audience or with anyone knowledgeable in their customs and culture (Kövecses, 2005). For example, in the statement, "it was a 
roller coaster", the reader needs to be conversant with the 'roller coaster' which is an entertainment found in an amusement parks in the western countries.

The most common type of metaphors identified were those classified as universal at $99 \%$, followed by those articles that had no any type of metaphor used at $1 \%$. Given that a majority of the newspapers' readers are thought to be literate (Oriare \& Mshindi, 2008; Simiyu, 2013), then using metaphors that were universal may have made it easier for them to understand the Sino-Kenya relations because they had prior knowledge of the universal culture as opposed to those who could not understand the metaphors. For example, when a Standard newspaper journalist was quoted as terming the relations as being 'fireworks' (Daily Nation, September 23, 2011). Fireworks are devices that may be alien to the reader who doesn't know what they are or when they are used. Thus, such a metaphor can be understood well by a reader who is conversant with the western culture, where fireworks are used in celebrations. On the other hand, by using universally understood metaphors, the media made sure that it cut across a wider audience. For example, when they quoted one of the Chinese diplomat referring to himself as a 'fire-fighter of poor (The Standard, September 22, 2011). In this example, it is assumed that everyone can relate to the fire-fighter and the crucial role he played in saving lives and that in his endeavor to perform his duty, he might have made a mistake and instead of appreciating his hard work, the statement was mistaken. Such a way of understanding the two metaphors can lead to the reader either to support the relationship or not.

\section{Conclusion}

This study argues that the aim of mediatization is to make a phenomenon understandable by providing points of reference through the various interpretations of nature of mediatization such as tone, metaphor, and antinomies. In line with the first objective of the study, the data that was analysed showed that the two newspapers used various nature of mediatization such as tone, photographs and antinomies that served in mediatizing Sino-Kenya relations within known spheres that their audiences could relate to, thereby promoting deeper knowledge about the relationship.

Therefore, while the newspapers' mediatization of Sino-Kenya relations may have contributed to creating awareness of the relations, it portrayed it as not a win-win relations but a loop sided one by using various nature of mediatization such as metaphors that enhanced the theme of economic gain to China rather than both states, antinomies that forced the reader to pick a side to support; photographs that evoked various emotions. However, as Moscovici, (1993) posits, an idea, no matter what form it assumes, has the power of making us come together and modify our feelings and behaviour. This conclusion supports Gagliardone, Repnikova and Stremlan (2010) in their paper "China in Africa: A new approach to media development" argue that Chinese media seek to demonstrate the positive aspects of Chinese media engagement in Africa.

The results of this study further confirmed that media discourse plays an important role in promoting good understanding of the relationship by the Kenyan and Chinese audience by exploring the themes. It has also been ascertained that the ways through which the newspapers present their news, views and opinions about events involving inter-state relations can influence the attitudes, perceptions, thoughts and opinion of the public about the relations.

\section{References}

Achberger, J. (2010). The Dragon Has Not Just Arrived: The Historical Study of Africa's Relations with China. History Compass, 8(5), 368-376.

Baillie, R. K. (1996). Determining the effects of media portrayals of alcohol: going beyond short term influence. Alcohol and Alcoholism, 31(3), 235-242.

Brautigam, D. (2011a). Chinese development finance in Africa. Retrieved December: 21, 2012 from AmericanUniversitylibrary http://www.eastasiaforum. Org/2011/12/25/Chinese-development-aid-in-Africa/

Brautigam, D. and Gaye, A. (2009). Is Chinese investment Good for Africa? Retrieved January15, 2013 from http:// /www.cfr.org/china/chinese-investmentgood-africa/p12622

Creswell, J. W. (2014). A concise introduction to mixed methods research. SAGE publications.

Deacon et al. (Ed). (2007). Researching communications: A practical guide to methods in media and cultural analysis. London: Bloomsbury

Dijk, T. (1988). News as Discourse. Hillsdale: Lawrence Erlbaum Associates. ed.). Boston:discourse under construction, Ecquid Novi: African Journalism Studies, 34: 3, 79-1-1 dissertation, MSc Dissertation. London School of Economics and Political Science). document design, 13(1).

Hall, S., Critcher C., Jefferson T., Clarke J., \& Roberts, B. (1978): Policing the Crisis. Mugging, the State and Law and order. London, New York, Johannesburg: Macmillan. Hamburg: Africa Department, Economic Affairs (2008).

Hjavard, S., \& Lundby, K (2015). Mediatization: theorizing the interplay between media, culture and society. Media, Culture \& Society, 37(2), 314-324. 
Ivankova, N. V., \& Greer, J. L. (2015). Mixed methods research and analysis. Research methods in applied linguistics: A practical resource, 63-81.

Iyengar, S. (1991). Mass media and elections: An overview. American Politics Quarterly, 19(1), 109-139.

Jiang, W. (2009). Fuelling the dragon: China's rise and its energy and resources extraction in Africa. The China Quarterly, 585-609. Journalism Studies Volume 15, 2014 - Issue 3Perspectives Journalism Studies, 15(3), 243-255.Journalism. " in De Burgh, H. (ed.), Investigative Journalism: Context and Practice. London: Rutledge, pp. 89-107.

Kamau P. (2007). Kenya: A case study-The Developmental Impact of Asian Drivers on Kenya with Emphasis on Textiles and Clothing Manufacturing. Mimeo.

Krippendorff, K. (2003) Content analysis: An introduction to its methodology ( $2^{\text {nd }}$ ed.). London, UK: SAGE.

Kurlantzick, J. (2007). Charm offensive: How China's soft power is transforming the world. New Haven: Yale University Press.

Lacy et.al, (2001). Sample Size for Newspaper Content Analysis in Multi-Year Studies. Journalism and Communication Quarterly, 78(4), 836-845.

Lai, H and Yiyi L. (2012) China's soft power and International relations. Routledge

Lam, H (2011). Empirical studies in information visualization: Seven scenarios. IEEE transactions on visualization and computer graphics, 18(9), 1520-1536.

Large, D. (2008). Beyond 'dragon in the bush': the study of China-Africa relations. African affairs, 107(426), 45-61.

Le Pere, G. (Ed.). (2007). China in Africa: Mercantilist predator, or partner in development?

Leavy, P. (2000) Feminist content analysis and representative characters. The Qualitative Report, 5(1) (pp.1-16). Retrieved from http://www.nova.edu/ssss/QR/QR5- 1/leavy.html

Leedy, P. D., \& Ormrod, J. E. (2010) Practical research: Planning and design (9th ed.). Merrill, NJ: Pearson Education Inc.

MacKay, K. J., \& Fesenmaier, D. R. (1997). Pictorial element of destination in image formation.

Marková, I. (2003). Dialogicality and social representations. The dynamics of mind. Cambridge, UK: Cambridge University Press.mass media and environmental issues, 51-68.

Mayring, P. (2004). Qualitative content analysis. A companion to qualitative research, 1(2), 159-176.

Mboya, C. O. (2015). Chinese print media's portrayal of china in Africa: a case of China daily Africa (Doctoral dissertation, University of Nairobi).

McCombs, M. \& Reynolds. A. (2002). News Influence on Our Pictures of the World. In J. Bryant

Mingxun, Z. Robertson, T.S. (2013) On equal terms: redefining China's relationship with America \& the west. Hoboken, NJ: Wiley.

Ministry of Planning and National Development Kenya. (2003). Economic Recovery Strategy for Wealth and Employment Creation 2003-2007. Nairobi: Government of Kenya.

Mohammed, S. N., and R. C. Trumpbour. 2020. "The mediatization in the 2016 U.S. Presidential

Moscovici, S. (1984). The phenomenon of social representations. Social representations., 3-69.

Muekalia, D. J. (2004), Africa and China's strategic partnership. African Security Review 13(1):5-11

Murdock, G. (1999). Corporate dynamics and broadcasting futures. The Media Reader: Continuity and Transformation, 28-42.

Neuendorf, K. A. (2002). The content analysis guidebook. Thousand Oaks, CA: Sage Newsweek, and Time. Northwestern University Press.

Nyabuga, G (2009) Mediatizing Politics and Democracy: Making sense of the role of the media in Kenya. Media Focus on Africa Foundation Nairobi

Nyabuga, G., \&. Booker, N. (2013). Kenya, Country Report. Retrieved from Nairobi,

Nyamnjoh, F. B. (2005). Africa's media, democracy and the politics of belonging. Zed Books.

Odhiambo, A. (2012). Kenya signs deal with China to curb counterfeits. Available at of Consumer Culture, $10(1), 105-128$.

Ogenga, F. (2008): The Role of the Kenyan Media in the 2007 Elections. EISA Journal of African Election. Vol. 7 Issue 2: 124-134.

Ogenga, F. (2010). Political-Economy of the Kenyan Media - Towards a Culture of Active Citizen Journalism. Global Media Journal African Edition. Vol. 4 No.2: 151-162.

Ogenga, F. (2011). Mugabe Must Go: Textual Meanings of the Mediatization of the Zimbabwean Situation by the South African Press. Africa Conflict and Peace Building Review. Indiana: Indiana University Press. Vol. 1 No. 1: 39-70.

Ogenga, F. (2012). Is Peace Journalism Possible in the War Against Terror in Somalia? How the Kenyan Daily Nation and the Standard Represented Operation Linda Nchi. Conflict and Communication Online. Vol. 11 No. 2: 1-14.

Ogutu, K. (2016, July 4th 2016). Chinese Fish Floods Kisumu Markets. The Standard. Retrieved from 
https://www.standardmedia.co.ke/article/2000207446/chinesefish- floods-kisumu-markets

Okoth, E. (March 26th, 2016). Chinese Firms Hire More Locals Than Foreigners: Report. The Daily Nation.

Olomojobi, O. T. (2017). National newspapers' coverage of the conflict between herders and farmers in Nigeria. (Unpublished MSc dissertation), Babcock University, Ilishan-Remo, Ogun State, Nigeria.

Ongiri, I. (2013). Protest as Jubilee election losers and cronies picked to head parastatals. Daily nation. Sunday. iongiri@ke. nationmedia.com.

Onjala, J. (2008, 5th March). A Scoping Study of China-Africa Economic Relations: A case study of Kenya. Nairobi, Kenya: Institute of Development Studies, University of Nairobi.

Schudson, M. (2003): The Sociology of News Production. New York: Longman

Strömbäck, J., \& Esser, F. (2014). Introduction: making sense of the mediatization of politics.

Sun, W. and Sinclair, J. (2015) Media and Communication in the Chinese Diaspora; Rethinking

Taylor, I. et al (2014) China's Rise in Africa (end): Perspectives on a Developing connection. the Bild, 19902002. Harvard International Journal of Press/Politics, 8(3), 54-69.

The Guardian. (2002, 12 30). Kibaki sworn in as Kenyan president. Retrieved 07 28, 2017, from The Guardian: https://www.theguardian.com/world/2002/dec/30/kenya

Tull M. D. (2006) China's engagement in Africa: Scope, Significance and Consequences, Journal of Modern African Studies, 44:3, 459-479.

Umejei, E. L. (2013). The framing of China in Nigeria: an analysis of the coverage of China's involvement in Nigeria by Thursday newspaper (Doctoral dissertation, Rhodes University).

Wei, T (2015). A Comparative Analysis of Chinese, Western and African Media Discourse in the Representation of China's Expansion of Economic Engagements in Africa http://www.lse.ac.uk/media@1se/research/mediaWorkingPapers/ElectronicMScDissertationSeries.aspx

Williams, C. (2007) Research methods. Journal of Business \& Economics Research, 5(3), 65-72. Retrieved from http://www.cluteinstitute.com/ojs/index.php/JBER/article/view/2532 